\title{
Fontes energéticas vegetais para juvenis de jundiá e carpa
}

\author{
[Plant-energy sources for jundiá and carp juvenile] \\ V. Corrêia ${ }^{1}$, L.P. Silva ${ }^{1}$, F.A. Pedron ${ }^{1}$, R. Lazzari ${ }^{2}$, C.C. Ferreira ${ }^{1}$, J. Radünz Neto ${ }^{1}$ \\ ${ }^{1}$ Universidade Federal de Santa Maria - Santa Maria, RS \\ ${ }^{2}$ Universidade Federal de Santa Maria - CESNORS - Palmeira das Missões, RS
}

\begin{abstract}
RESUMO
Para avaliar o desempenho, o metabolismo e a composição corporal de juvenis de jundiá (Rhamdia quelen) e de carpa húngara (Cyprinus carpio) alimentados com fontes energéticas vegetais, foi conduzido experimento de 60 dias. Três dietas compostas por aveia descascada, farelo de arroz desengordurado estabilizado (FADE) ou por farelo de trigo e milho (dieta-controle) foram ofertadas três vezes ao dia a 360 juvenis de jundiá $(5,59 \pm 0,06 \mathrm{~g})$ ou de carpa húngara $(5,82 \pm 0,14 \mathrm{~g})$ distribuídos em 18 tanques $(280 \mathrm{~L})$, totalizando nove tanques por espécie. Não foram observadas diferenças significativas no desempenho das espécies estudadas. Em relação aos parâmetros metabólicos, as menores concentrações séricas de colesterol total no jundiá foram verificadas nas dietas com aveia $(214,49 \mathrm{mg} / \mathrm{dL})$ e FADE $(216,3 \mathrm{mg} / \mathrm{dL})$, enquanto para a carpa húngara as menores concentrações observadas foram nos peixes alimentados com FADE $(222,54 \mathrm{mg} / \mathrm{dL})$. Quanto à composição centesimal, os valores de gordura no filé foram menores nos jundiás dos tratamentos controle $(3,76 \%)$ e aveia $(3,95 \%)$. A inclusão de aveia proporcionou menor deposição de gordura corporal em ambas as espécies. Conclui-se que $20 \%$ de aveia descascada ou de farelo de arroz desengordurado podem ser incluídos na dieta de juvenis de jundiá e de carpa húngara sem prejuízos para o crescimento.
\end{abstract}

Palavras-chave: aveia descascada, composição corporal, Cyprinus carpio, farelo de arroz desengordurado, Rhamdia quelen

\begin{abstract}
In order to evaluate the performance, metabolism and body composition of jundia (Rhamdia quelen) and common carp (Cyprinus carpio) juvenile fed with plant-energy sources, the experiment was conducted during 60 days. Three diets composed of husked oats, defatted rice bran stabilized (FADE) or wheat bran and corn (control diet) were provided three times daily to 360 jundiá juveniles $(5.59 \pm 0.06 \mathrm{~g})$ or common carp $(5.82 \pm 0.14 \mathrm{~g})$ distributed into 18 tanks $(280 \mathrm{~L})$, totaling nine tanks per species. There were no significant differences in performance parameters in both species. For metabolic parameters, the lowest serum levels of total cholesterol in jundiá were observed in diets containing oats $(214,49 \mathrm{mg} / \mathrm{dL})$ and FADE $(216,3 \mathrm{mg} / \mathrm{dL})$, while for the common carp the lowest levels were observed in fish fed FADE $(222,54 \mathrm{mg} / \mathrm{dL})$. As for the composition, the fat in the fillet was lower in the jundia from control $(3,76 \%)$ and oats $(3,95 \%)$ treatments, providing the lowest body fat deposition in both species. The inclusion of oats showed lower body fat deposition in both species. It is concluded that the inclusion of $20 \%$ stabilized husked oats or defatted rice bran in the diet of jundia and common carp juvenile does no harm to growth.
\end{abstract}

Keywords: body composition, Cyprinus carpio, stabilized defatted rice bran, husked oats, Rhamdia quelen

\section{INTRODUÇÃO}

A alimentação é de grande importância na aquicultura, pois influencia no metabolismo, no crescimento, na qualidade de carcaça, na saúde dos animais e, consequentemente, na eficiência da atividade. Ingredientes como o milho e o

Recebido em 4 de março de 2011

Aceito em 3 de abril de 2012

E-mail: vivianicorreia@hotmail.com farelo de trigo são frequentemente utilizados como fontes energéticas na formulação de dietas para peixes. Contudo, a elevação de preços destas fontes, devido a prejuízos na produção agrícola causados por intempéries climáticas ou pela sazonalidade de produção, irá causar aumento nas despesas com a produção. Dessa

Arq. Bras. Med. Vet. Zootec., v.64, n.3, p.693-701, 2012 
forma, é relevante o estudo de matérias-primas alternativas, buscando ingredientes com qualidade, padronização de nutrientes e disponibilidade regional com menor custo (Nagae et al., 2001).

A utilização de fontes energéticas de origem vegetal em dietas para peixes ainda é limitada devido à baixa palatabilidade, à deficiência de aminoácidos e a fatores antinutricionais (Francis et al., 2001). No entanto, estes ingredientes contêm altos teores de carboidratos, grande disponibilidade e menor custo se comparados às fontes proteicas. Além disso, quando incluídos adequadamente nas dietas, não prejudicam o desempenho dos animais e propiciam que os aminoácidos sejam poupados do catabolismo para fornecimento de energia e passem a ser utilizados para crescimento e mantença. Isto ocorre porque a glicose originada da digestão e absorção dos carboidratos é o substrato preferido a ser oxidado pelas células sanguíneas e pelo tecido nervoso (Hemre et al., 2002; Valente et al., 2009).

O amido é o principal carboidrato armazenado nos grãos e em seus subprodutos, sendo que seu aproveitamento pelos peixes irá depender da complexidade da molécula (amilose/amilopectina), da concentração de inclusão e do processamento da fonte utilizada, assim como do hábito alimentar da espécie (Hemre et al., 2002; Svihus et al., 2005).

As diferenças quanto ao aproveitamento do carboidrato entre as espécies se devem às particularidades anatômicas e às atividades digestivas endógenas de cada hábito alimentar (Krogdahl et al., 2005). Os peixes de hábitos onívoro e herbívoro possuem maior capacidade de utilizar este nutriente como fonte de energia do que os carnívoros, visto que estes animais podem sofrer adaptações morfológicas e absortivas de acordo com a disponibilidade de alimento (Abelha et al., 2001).

Diante disso, o objetivo deste trabalho foi avaliar a inclusão de aveia descascada ou de farelo de arroz desengordurado como fontes energéticas alternativas em dietas para a carpa húngara (Cyprinus carpio) e o jundiá (Rhamdia quelen) e suas respostas quanto ao desempenho, às características de carcaça, ao metabolismo e à composição corporal.

\section{MATERIAL E MÉTODOS}

Após aprovado pelo Comitê de Ética e Bem-Estar Animal da Universidade Federal de Santa Maria (Número do processo: 23081.006971/2009-52), o experimento foi conduzido no Laboratório de Piscicultura da UFSM, no período de janeiro a março de 2009 , totalizando 60 dias. Utilizou-se sistema com recirculação de água, composto por dois filtros biológicos, um reservatório (2000L) dotado de aquecimento (resistências-2000W) e 18 tanques experimentais (280L). Durante 20 dias, 2000 juvenis de jundiá e de carpa húngara foram adaptados às condições experimentais, recebendo, durante este período, ração peletizada (32\% PB). Destes peixes selecionaram-se 720 juvenis, quando os jundiás possuíam $5,59 \pm 0,06 \mathrm{~g}$ de peso médio inicial, e as carpas $5,82 \pm 0,14 \mathrm{~g}$. Os animais foram alojados em monocultivo, na densidade de 40 juvenis por tanque $(0,8 \mathrm{~g} / \mathrm{L})$. Para obtenção de dados iniciais de rendimento de carcaça, índices digestivos e composição centesimal do peixe inteiro, foram abatidos, por hipotermia (imersão em água + gelo 1:1), 10 peixes de cada espécie.

A análise de qualidade da água foi realizada semanalmente, exceto oxigênio dissolvido e temperatura, que foram verificados diariamente. Para medição do oxigênio dissolvido e da temperatura, utilizou-se oxímetro digital (modelo $550 \mathrm{~A}-\mathrm{YSI}^{\circledR}$ ). Na avaliação do nitrito, da amônia total, da alcalinidade e do $\mathrm{pH}, \mathrm{fez}-\mathrm{se}$ o uso de kit colorimétrico Alfakit $^{\circledR}$. Os parâmetros físicos e químicos da água mantiveram-se dentro das concentrações aceitáveis para peixes de águas temperadas, durante o período experimental (Arana, 2004): 0,22 $\pm 0,05 \mathrm{ppm}$ de amônia total; $0,10 \pm 0,05 \mathrm{ppm}$ para nitrito; $26,14 \pm 0,39^{\circ} \mathrm{C}$ de temperatura média; $5,08 \pm 0,36 \mathrm{ppm}$ de oxigênio dissolvido; $40,00 \pm 3,44 \mathrm{mg} \quad \mathrm{CaCO}_{3} \mathrm{~L}^{-1}$ para alcalinidade e 7,36 $\pm 0,09$ de $\mathrm{pH}$.

Foram avaliadas três dietas peletizadas (Tab. 1), em três repetições: uma dieta com inclusão de aveia descascada, outra com farelo de arroz desengordurado estabilizado e uma dieta-controle (farelo de trigo e milho), em delineamento inteiramente casualizado. Antes da oferta do alimento, foi realizada a limpeza (sifonagem) dos tanques, para retirada de fezes e eventuais sobras de alimento. As dietas foram ofertadas três vezes ao dia $(9,13$ e $17 \mathrm{~h})$, sendo 
que, até os 30 dias experimentais, foram ofertados $6 \%$ da biomassa/dia, e nas semanas seguintes, ofertaram-se $4 \%$ para os juvenis de jundiá e $5 \%$ para os de carpa húngara. A cada 10 dias de experimento, foi realizada a pesagem dos animais, com todos os peixes do respectivo tanque capturados e pesados ao mesmo tempo, para ajuste da quantidade de ração.

Tabela 1. Formulação, composição centesimal (\%) e de aminoácidos das dietas experimentais utilizadas no experimento ${ }^{1}$

\begin{tabular}{|c|c|c|c|}
\hline \multirow[t]{2}{*}{ Ingrediente } & \multicolumn{3}{|c|}{ Tratamentos (\%) } \\
\hline & Controle $^{2}$ & Aveia $^{3}$ & $\mathrm{FADE}^{4}$ \\
\hline Farelo de soja & 28,6 & 23,0 & 15,4 \\
\hline Concentrado proteico de soja $60 \%$ & 3,6 & 7,3 & 14,0 \\
\hline Farinha de carne suína & 38,0 & 32,8 & 32,4 \\
\hline Farelo de trigo & 5,1 & 8,6 & - \\
\hline Milho & 14,6 & - & 6,0 \\
\hline Aveia descascada & - & 20,0 & - \\
\hline FADE & - & - & 20,0 \\
\hline L-Lisina & 0,27 & 0,44 & 0,57 \\
\hline DL-Metionina & 0,57 & 0,59 & 0,58 \\
\hline Mistura vitamínica $^{5}$ & 1,0 & 1,0 & 1,0 \\
\hline Cloreto de colina $^{5}$ & 1,0 & 1,0 & 1,0 \\
\hline Mistura mineral $^{5}$ & 1,0 & 1,0 & 1,0 \\
\hline Calcário calcítico & - & 0,5 & 1,0 \\
\hline Cloreto de sódio & 0,5 & 0,5 & 0,5 \\
\hline Óleo de soja & 6,6 & 4,3 & 7,7 \\
\hline \multicolumn{4}{|c|}{ Composição centesimal } \\
\hline Matéria seca $^{6}$ & 94,87 & 95,29 & 95,27 \\
\hline Proteína bruta $^{6}$ & 37,73 & 37,51 & 37,45 \\
\hline Lisina & 1,72 & 1,56 & 1,42 \\
\hline Metionina & 0,49 & 0,48 & 0,48 \\
\hline Treonina & 1,47 & 1,42 & 1,41 \\
\hline Triptofano & 0,68 & 0,63 & 0,57 \\
\hline Valina & 1,51 & 1,46 & 1,36 \\
\hline Isoleucina & 1,37 & 1,30 & 1,17 \\
\hline Leucina & 2,28 & 2,17 & 1,93 \\
\hline Fenilalanina & 1,50 & 1,50 & 1,46 \\
\hline Histidina & 0,81 & 0,77 & 0,75 \\
\hline Arginina & 2,66 & 2,66 & 2,85 \\
\hline Matéria mineral $^{6}$ & 12,21 & 11,72 & 13,96 \\
\hline Cálcio ${ }^{6}$ & 2,54 & 2,28 & 2,58 \\
\hline Fósforo ${ }^{6}$ & 1,58 & 1,45 & 1,83 \\
\hline Fibra em detergente neutro ${ }^{7}$ & 20,41 & 17,38 & 19,50 \\
\hline Amido disponível $^{8}$ & 10,40 & 15,63 & 10,22 \\
\hline Carboidratos solúveis em detergente neutro & 9,88 & 15,64 & 10,14 \\
\hline Extrato etéreo $^{6}$ & 14,64 & 13,04 & 14,22 \\
\hline Energia digestível $(\mathrm{kcal} / \mathrm{kg})^{9}$ & $3.296,23$ & $3.291,79$ & $3.253,53$ \\
\hline
\end{tabular}

${ }^{\mathrm{T}}$ Dietas ajustadas a partir de Lazzari et al. (2006). ${ }^{2}$ Controle: farelo de trigo + milho; ${ }^{3}$ aveia: aveia descascada; ${ }^{4}$ FADE: farelo de arroz desengordurado estabilizado. ${ }^{5}$ Composição da mistura vitamínica e mineral (por kg de produto/Mig Plus ${ }^{\circledR}$ ): ác. fólico: $3000 \mathrm{mg}$, ác. pantotênico: $30000 \mathrm{mg}$, cobalto: $20 \mathrm{mg}$ cobre: $2000 \mathrm{mg}$, colina: $800000 \mathrm{mg}$, ferro: 30000mg, biotina: $500 \mathrm{mcg}$, iodo: $900 \mathrm{mg}$, manganês: $5000 \mathrm{mg}$, selênio: $100 \mathrm{mg}$, vit.A: $10000000 \mathrm{UI}$, vit. B1: $8000 \mathrm{mg}$, vit. B2: 10000mg, vit. B6: $8000 \mathrm{mg}$, vit. B12: $20000 \mathrm{mcg}$, vit. C: $150000 U$, vit. D: 2000000 UI, vit. E: $150000 \mathrm{mg}$, vit. K: 6000UI, zinco: 20000mg, inositol $88000 \mathrm{mg}$, niacina $60000 \mathrm{mg}$. ${ }^{6}$ Analisada- Nutron Alimentos LTDA.; ${ }^{7}$ Analisados - Laboratório de Bromatologia e Nutrição de Ruminantes - DZ/UFSM. ${ }^{8}$ Analisado - Laboratório de Piscicultura (UFSM). ${ }^{9}$ Calculada: energia digestível $=[(\mathrm{PB} * 5640 \quad \mathrm{kcal} / \mathrm{kg} * 0,85)+(\mathrm{EE} * 9440 \mathrm{kcal} / \mathrm{kg}$ $\left.* 0,9)+\left(\mathrm{CSDN}^{*} 4110 \mathrm{kcal} / \mathrm{kg} * 0,60\right)\right]$ (ajustada de acordo com Meyer et al., 2004). 
Aos 60 dias experimentais, os animais foram submetidos a jejum de 24h, anestesiados em trifenoxietanol $(0,03 \%)$, pesados e medidos individualmente, para o cálculo das seguintes características zootécnicas: conversão alimentar aparente: CAA $(\mathrm{kg} / \mathrm{kg})$; ganho em peso médio diário: GPD (g/dia); ganho de peso relativo: GPR $(\%)$; taxa de crescimento específico: TCE $(\% /$ dia $)=[(\ln ($ peso final $)-\ln ($ peso inicial $)) /$ dias $]$ $\mathrm{x}$ 100, sendo: $\mathrm{In}=$ logaritmo neperiano; $\mathrm{e}$ taxa de eficiência proteica: $\mathrm{TEP}=$ ganho em peso/proteína ingerida $(\mathrm{g})$.

No final do experimento, foram abatidos por hipotermia e eviscerados seis peixes de cada espécie por tratamento, para obtenção dos dados de peso de carcaça, filé, fígado e trato digestório. Dos mesmos juvenis de jundiá abatidos para a coleta destes valores retiraram-se amostras de filé, sendo estas refrigeradas para posterior análise de composição centesimal. A partir destes dados, foram calculados, por meio da relação entre o peso do órgão e o peso do peixe inteiro, o rendimento de carcaça, o rendimento de filé, o índice digestivossomático e o índice hepatossomático, expressos em porcentagem $(\%)$.

Também aos 60 dias, seis juvenis de cada espécie por tratamento foram abatidos por hipotermia e triturados, sendo as amostras congeladas para posterior análise da composição centesimal do peixe inteiro. A gordura foi extraída e quantificada seguindo o método de Bligh e Dyer (1959). A proteína bruta foi determinada pelo método de micro-Kjeldahl usando-se $\mathrm{PB}=\mathrm{N} \times$ 6,25. Para determinação da umidade, as amostras foram colocadas em estufa por quatro horas a $60^{\circ} \mathrm{C}$ e, $\log$ o após, a $105^{\circ} \mathrm{C}$ por oito horas, e o teor de cinzas foi determinado em mufla $\left(550^{\circ} \mathrm{C}\right)$. Estas metodologias estão descritas na AOAC (1995). Com os resultados obtidos, foram calculados: deposição de proteína corporal: $\mathrm{PBTD}(\mathrm{g})=[\mathrm{Pf} *(\% \mathrm{PBCf} / 100)]-[\mathrm{Pi} *$ (\%PBCi/100)]; deposição de gordura corporal: $\mathrm{GTD}(\mathrm{g})=\left[\begin{array}{llll}\mathrm{Pf} & * & (\% \mathrm{GCf} / 100)\end{array}\right]-[\mathrm{Pi} *$
(\%GCi/100)], sendo: Pi e Pf= peso inicial e final , $\mathrm{PBCi}$ e $\mathrm{PBCf}=$ proteína corporal inicial e final, $\mathrm{GCi}$ e $\mathrm{GCf}=$ gordura corporal inicial e final.

Igualmente, no final do experimento, após jejum de 12 horas, foram coletadas amostras de sangue (12 amostras de cada espécie por tratamento), que foram centrifugadas a $3000 \mathrm{rpm} / 10$ minutos. O soro obtido foi refrigerado, e, posteriormente, realizaram-se as análises de: triglicerídeos $(\mathrm{mg} / \mathrm{dL})$, colesterol total $(\mathrm{mg} / \mathrm{dL})$, proteínas totais $(\mathrm{g} / \mathrm{dL})$ e albumina $(\mathrm{g} / \mathrm{dL})$, usando-se kits colorimétricos Doles ${ }^{\circledR}$.

Utilizou-se para as análises estatísticas o pacote estatístico SAS/2001, versão 8.2. Inicialmente, realizou-se análise de detecção das observações aberrantes (outliers) em todos os dados, sendo excluídas as observações maiores ou menores que a média $\pm 2 \times$ desvio-padrão. Após, foram aplicados o teste de normalidade (Shapiro-Wilk) e a análise de variância. As médias, quando significativas $(\mathrm{P}<0,05)$, foram comparadas pelo teste Tukey. As variáveis que não apresentaram distribuição normal foram submetidas à ANOVA de Kruskall-Wallis.

\section{RESULTADOS E DISCUSSÃO}

Ao final do período experimental, não foram verificadas diferenças significativas nas características zootécnicas de ambas as espécies (Tab. 2). Cabe destacar o bom desempenho dos juvenis de jundiá, com taxa de crescimento específico, ganho em peso relativo e conversão alimentar aparente de 3,9-4,0\%/dia, 1009-1079\% e 1,1:1, respectivamente. Tal desempenho foi superior ao observado por Lazzari et al. (2006) $(\mathrm{CAA}=1,4-1,9$ e $\mathrm{TCE}=1,7-2,8)$ para juvenis de jundiá alimentados durante 60 dias com fontes proteicas (farinha de carne e ossos, farinha de peixe, farelo de soja e levedura). No presente trabalho, os frequentes ajustes na quantidade de alimento ofertado e o parcelamento dessa quantia em três vezes/dia podem ter maximizado o aproveitamento destas dietas pelos peixes. 
Fontes energéticas vegetais...

Tabela 2. Características zootécnicas dos juvenis de jundiá e de carpa húngara alimentados com dietas contendo fontes energéticas vegetais, aos 60 dias experimentais

\begin{tabular}{|c|c|c|c|c|c|}
\hline & \multicolumn{3}{|c|}{ Tratamentos } & \multirow[b]{2}{*}{$\mathrm{CV}$} & \multirow[b]{2}{*}{$\mathrm{p}$} \\
\hline & Controle & Aveia & FADE & & \\
\hline \multicolumn{6}{|c|}{ Jundiá } \\
\hline$P(g)$ & 62,00 & 64,24 & 65,92 & 12,43 & $\mathrm{~ns}$ \\
\hline $\mathrm{CT}(\mathrm{cm})^{\#}$ & 18,11 & 18,29 & 18,43 & 1,97 & ns \\
\hline $\mathrm{TCE}(\% / \mathrm{dia}) \#$ & 3,92 & 3,98 & 4,02 & 4,81 & $\mathrm{~ns}$ \\
\hline CAA & 1,12 & 1,12 & 1,10 & 5,28 & $\mathrm{~ns}$ \\
\hline TEP & 2,40 & 2,38 & 2,39 & 5,18 & ns \\
\hline GPD (g/dia) & 0,94 & 0,98 & 1,00 & 13,62 & ns \\
\hline GPR $(\%)$ & 1009,16 & 1049,31 & 1079,34 & 13,62 & $\mathrm{~ns}$ \\
\hline \multicolumn{6}{|c|}{ Carpa húngara } \\
\hline$P(g)$ & 26,52 & 24,35 & 25,82 & 8,59 & ns \\
\hline CT (cm) & 10,68 & 10,35 & 10,46 & 2,91 & ns \\
\hline TCE (\%/dia) & 2,52 & 2,37 & 2,47 & 6,18 & ns \\
\hline CAA & 2,27 & 2,22 & 2,16 & 4,01 & ns \\
\hline TEP & 1,27 & 1,24 & 1,23 & 3,23 & ns \\
\hline GPD (g/dia) & 0,34 & 0,30 & 0,33 & 11,13 & ns \\
\hline GPR $(\%)$ & 354,96 & 317,75 & 342,90 & 11,13 & ns \\
\hline
\end{tabular}

Controle: farelo de trigo + milho; aveia: aveia descascada; FADE: farelo de arroz desengordurado estabilizado; P: peso; CT: comprimento total; TCE: taxa de crescimento específico; CAA: conversão alimentar aparente; TEP: taxa de eficiência proteica; GPD: ganho em peso diário; GPR: ganho em peso relativo. CV: coeficiente de variação; ns= não significativo $(\mathrm{P}>0,05) ;{ }^{\#}$ ANOVA de Kruskall-Wallis.

O bom crescimento dos juvenis nas três dietas testadas também pode ser explicado pelo equilíbrio nutricional das formulações (Tab. 1). Além disso, pode-se salientar que o FADE contém maiores teores de vitaminas e minerais (Pestana et al., 2008). Entre as vitaminas, destacam-se tiamina, niacina e riboflavina, que são importantes no metabolismo de carboidratos, lipídeos e proteínas. Já o magnésio atua como ativador de enzimas do metabolismo de carboidratos e em reações de síntese proteica (Webster e Lim, 2002). Do mesmo modo, os bons resultados apresentados pelos peixes na dieta com aveia podem ser justificados pela ausência da casca, que reduz os fatores antinutricionais, assim como pelo teor lipídico, pela qualidade proteica e pelo poder antioxidante deste grão (Peterson, 2001).

Resultados semelhantes ao presente estudo foram obtidos por Przybyl e Mazurkiewicz (2004) em carpa comum (Cyprinus carpio L.), ao avaliarem dietas compostas com cevada, trigo, triticale e arroz. Os autores não detectaram diferença significativa para ganho de peso, taxa de crescimento específico, conversão alimentar aparente e taxa de eficiência proteica. Hemre e Hansen (1998) também não verificaram diferença significativa no peso e na taxa de crescimento específico para juvenis de salmão (Salmo salar) alimentados com diferentes fontes de amido gelatinizado (trigo, milho e aveia). No entanto, os peixes alimentados com trigo apresentaram menor consumo e menor conversão alimentar aparente, assim como maior taxa de eficiência proteica. Os autores citaram que o trigo proporcionou melhor efeito poupador de proteína.

Signor et al. (2007) não detectaram efeito das concentrações de inclusão de triguilho $(0 ; 7,97$; 14,$94 ; 23,91$ e $31,88 \%$ ) sobre peso final, ganho em peso e conversão alimentar aparente da tilápia-do-nilo (Oreochromis niloticus) com substituição de até $100 \%$ do milho. Porém, em outro trabalho realizado com esta mesma espécie durante a fase de reversão sexual, Meurer et al. (2004) observaram efeito linear significativo $(\mathrm{p}<0,01)$ da concentração de milheto $(0 ; 2 ; 4 ; 6$; 8 e 10\%) para peso final. Os pesquisadores acreditam que esse resultado positivo no peso possa estar relacionado às concentrações de amido na ração $(1,6$ a 7,1\%), já que esta espécie possui eficiente aproveitamento desta fração (Boscolo et al., 2008). No presente estudo, a dieta com aveia possuía $15,6 \%$ de amido disponível, enquanto a FADE e a controle possuíam 10,2 e $10,4 \%$, respectivamente, sendo 
indiferente o desempenho de ambas as espécies no período experimental. Desse modo, percebese o bom aproveitamento do amido por estes peixes.

Quanto aos parâmetros de rendimento de cortes e aos índices digestivos, não foram detectadas diferenças significativas entre as dietas para ambas as espécies (Tab. 3). Em estudos anteriores com estes peixes (Pedron et al., 2008; Bergamin, 2010), também não foram verificadas variações nestes parâmetros devido a mudanças na fonte de fibra (casca de algodão ou de soja) e de proteína (farinha de carne suína, farelo de soja, farelo de canola, farelo de girassol e farelo de linhaça). Entretanto, valores inferiores de rendimento de carcaça (80-82\%) e superiores de rendimento de filé (34,3-40,0\%) foram registrados para juvenis de jundiá alimentados com combinações de fontes proteicas (Lazzari et al., 2006). A diferença de resultados em relação a rendimento de cortes entre os trabalhos é justificável, pois estes parâmetros, além do efeito da dieta, também são influenciados pela fase de vida, pelo peso dos resíduos e pela eficiência do manipulador ou de máquinas (ContrerasGuzmán, 1994).

Tabela 3. Rendimento de cortes, índices digestivos e parâmetros metabólicos (expressos por 100g de peso vivo) de peixes alimentados com dietas contendo fontes energéticas vegetais, aos 60 dias experimentais

\begin{tabular}{|c|c|c|c|c|c|}
\hline \multicolumn{6}{|c|}{ Tratamentos } \\
\hline & Controle & Aveia & FADE & $\mathrm{CV}$ & $\mathrm{p}$ \\
\hline \multicolumn{6}{|c|}{ Jundiá } \\
\hline $\mathrm{RC}(\%)$ & 86,41 & 85,37 & 85,06 & 1,92 & ns \\
\hline $\mathrm{RF}(\%)$ & 30,48 & 32,03 & 32,18 & 6,15 & ns \\
\hline $\operatorname{IDS}(\%)$ & 2,82 & 2,87 & 2,84 & 13,46 & ns \\
\hline IHS (\%) & 0,86 & 0,95 & 0,91 & 16,03 & ns \\
\hline $\mathrm{TG}(\mathrm{mg} / \mathrm{dL})$ & $996,93 b$ & $694,52 \mathrm{c}$ & $1367,36^{\mathrm{a}}$ & 9,29 & $* *$ \\
\hline $\mathrm{COL}(\mathrm{mg} / \mathrm{dL})$ & $265,72 \mathrm{a}$ & $214,49 b$ & $216,30 b$ & 5,86 & $* *$ \\
\hline PT (g/dL) & $5,33 a$ & $4,66 \mathrm{~b}$ & $4,47 b$ & 4,32 & $* *$ \\
\hline $\operatorname{ALB}(\mathrm{g} / \mathrm{dL})$ & $1,59 \mathrm{a}$ & $1,26 \mathrm{~b}$ & $1,57 \mathrm{a}$ & 4,98 & $* *$ \\
\hline \multicolumn{6}{|c|}{ Carpa húngara } \\
\hline $\mathrm{RC}(\%)$ & 83,52 & 82,87 & 85,07 & 3,43 & ns \\
\hline IDS (\%) $\#$ & 3,62 & 3,43 & 3,46 & 17,16 & ns \\
\hline IHS (\%) & 2,66 & 2,45 & 2,46 & 19,35 & ns \\
\hline $\mathrm{TG}(\mathrm{mg} / \mathrm{dL})$ & 575,72 & 561,59 & 553,51 & 14,20 & ns \\
\hline COL (mg/dL) & $297,31 \mathrm{a}$ & $274,77 \mathrm{a}$ & $222,54 b$ & 5,89 & $* *$ \\
\hline PT (g/dL) & 6,87 & 7,17 & 6,98 & 4,54 & ns \\
\hline $\operatorname{ALB}(\mathrm{g} / \mathrm{dL})$ & $2,29 b$ & $2,76^{\mathrm{a}}$ & $2,19 b$ & 8,29 & $* *$ \\
\hline
\end{tabular}

Controle: farelo de trigo + milho; aveia: aveia descascada; FADE: farelo de arroz desengordurado estabilizado; RC: rendimento de carcaça; RF: rendimento de filé; IDS: índice digestivossomático; IHS: índice hepatossomático; TG: triglicerídeos; COL: colesterol total; PT: proteínas totais; ALB: albumina. Médias com letras diferentes, na linha, indicam diferença significativa pelo teste de Tukey $(\mathrm{p}<0,05)$. CV: coeficiente de variação; ** $\mathrm{P}<0,01$; ns $=$ não significativo $(\mathrm{P}>0,05)$. " ANOVA de Kruskall-Wallis.

Em relação aos parâmetros metabólicos, observaram-se menores concentrações séricas de colesterol total para os juvenis de jundiá alimentados com a dieta com aveia e a FADE $(\mathrm{P}<0,01)$. Para este mesmo parâmetro, os juvenis de carpa húngara apresentaram menores concentrações no tratamento FADE (Tab. 3). Uma explicação para estes resultados é a presença de polissacarídeos não amiláceos nas fontes testadas, pois estes compostos, ao entrarem em contato com a água, tornam o bolo fecal maior e mais viscoso, fazendo com que a absorção de substâncias (glicose e colesterol) seja prejudicada, devido à menor ação das enzimas e dos sais biliares (Francis et al., 2001; Krogdahl et al., 2005).

Esta justificativa se confirma com os resultados das composições das dietas (Tab. 1), em que se observou alta concentração de fibra em detergente neutro (FDN) tanto na dieta FADE $(19,5 \%)$ como na dieta com aveia $(17,4 \%)$. No entanto, esta explicação não se verifica no tratamento-controle, pois, embora haja maior 
concentração de FDN (20,4\%) nessa dieta, os animais alimentados com ela apresentaram altos teores de colesterol total (Tab. 3). Acredita-se que esses valores superiores de colesterol total foram devido à maior incorporação de farinha de carne suína neste tratamento, que, por sua vez, possui alto teor de gordura $(19,5 \%)$.

As maiores concentrações séricas de triglicerídeos foram verificadas nos jundiás da dieta FADE, e as menores nos do tratamento com aveia (Tab. 3). Este resultado pode estar relacionado à necessidade de maior inclusão de óleo de soja nas dietas FADE e controle para que as rações fossem isoenergéticas. Em relação a este mesmo parâmetro, não foram verificadas diferenças significativas para os juvenis de carpa húngara. Estas maiores concentrações de triglicerídeos e menores concentrações de colesterol total também sugerem que tenha ocorrido síntese de triglicerídeo hepático (lipogênese).
Os juvenis de carpa húngara dos tratamentos controle e FADE apresentaram as menores concentrações de albumina sérica (Tab. 3). O oposto foi verificado com essas mesmas dietas para o jundiá, que apresentaram maiores concentrações de albumina. Tal fato pode estar relacionado aos maiores teores de triglicerídeos observados para esta espécie nestes tratamentos, pois os triglicerídeos são transportados no sangue combinados com albumina (Champe e Harvey, 1997).

Em relação ao teor de gordura no peixe inteiro para o jundiá e à deposição de gordura corporal para ambas as espécies, observou-se que os peixes do tratamento com aveia apresentaram os menores valores. Já os jundiás alimentados com FADE apresentaram maior teor de gordura no filé $(4,8 \%)$ se comparado às outras fontes (Tab. 4). Valores mais altos que esses foram constatados, com esta espécie, quando submetidos a diferentes fontes de proteína $(3,6-$ $6,5 \%$ ) (Lazzari et al., 2006) e de fibra $(5,4-7,2 \%)$ (Pedron et al., 2008).

Tabela 4. Composição centesimal do peixe inteiro e do filé (\%) e deposição de nutrientes em peixes alimentados com dietas contendo fontes energéticas vegetais, aos 60 dias experimentais

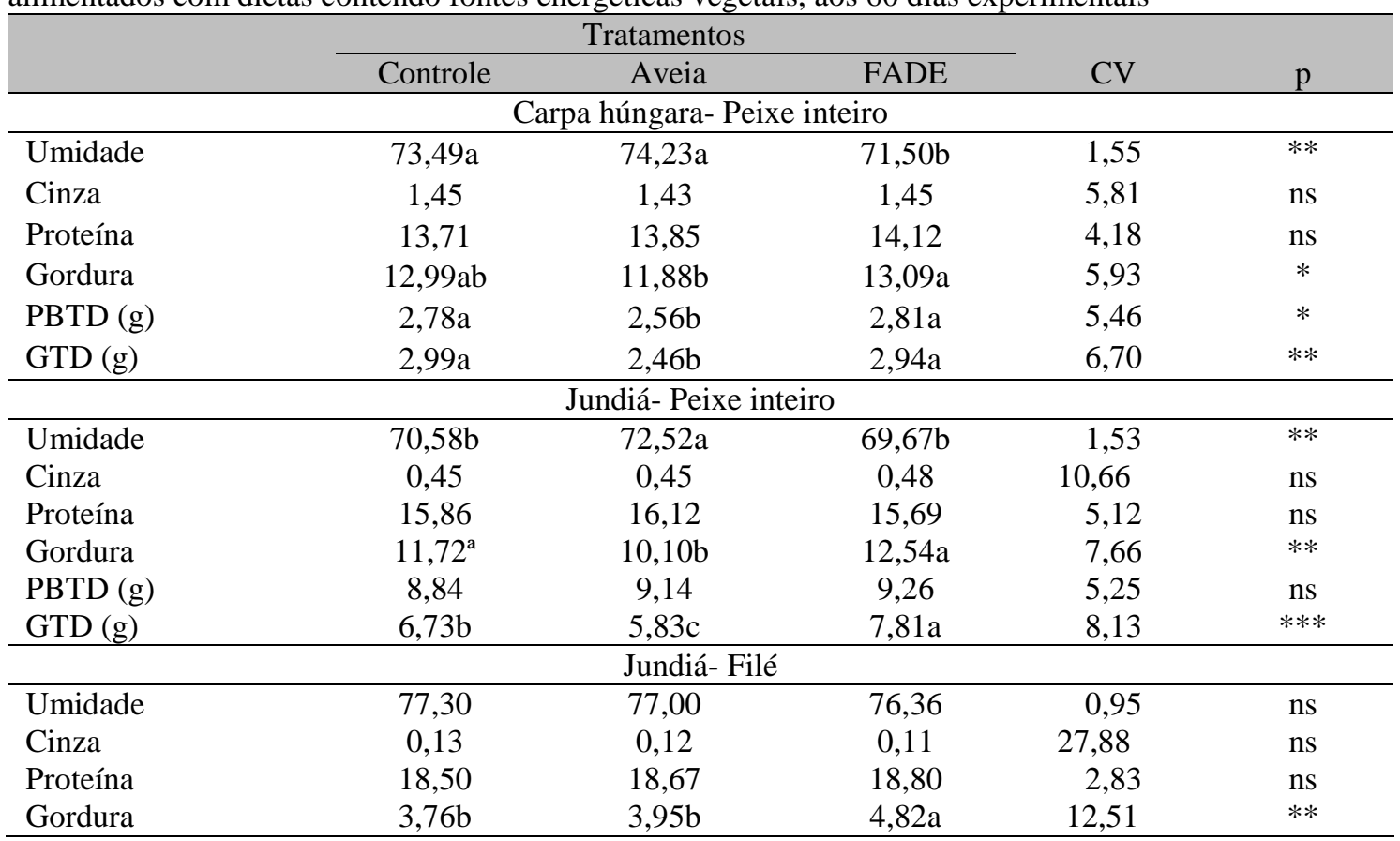

Controle: farelo de trigo + milho; aveia: aveia descascada; FADE: farelo de arroz desengordurado estabilizado; PBTD: proteína bruta total depositada; GTD: gordura total depositada. Médias com letras diferentes, na linha, indicam diferença significativa pelo teste Tukey $(\mathrm{P}<0,05) . \mathrm{CV}$ : coeficiente de variação; ns= não significativo $(\mathrm{P}>0,05) ;{ }^{*} \mathrm{p}<0,05 ; * * \mathrm{p}<0,01 ; * * * \mathrm{p}<0,0001$. 
Os elevados teores de gordura observados tanto nos resultados de composição do peixe inteiro quanto nos de retenção de nutrientes (Tab. 4), nas dietas controle e FADE, também podem ser explicados pela maior inclusão de farinha de carne suína e de óleo de soja, respectivamente. Da mesma forma, a espécie trabalhada, o sexo, a fase de vida, o sistema de cultivo adotado influenciam na composição da carne do peixe (Kubota e Emanuelli, 2004; Burkert et al., 2008). Para a maioria dos aquicultores, o que importa é o peso do peixe a ser entregue à indústria e a quantidade de carne obtida no final do processamento (Burkert et al., 2008). Porém, o conhecimento da composição química desta carne é fundamental no momento da elaboração e conservação dos produtos (Contreras-Guzmán, 1994).

\section{CONCLUSÕES}

Podem-se utilizar o farelo de arroz desengordurado estabilizado e a aveia descascada como fontes energéticas alternativas em concentração de $20 \%$ de inclusão, sem comprometer o desempenho de juvenis de jundiá e de carpa húngara. Além disso, a dieta com aveia descascada proporciona menor deposição de gordura corporal em ambas as espécies e menor teor de gordura no filé de jundiá.

\section{AGRADECIMENTOS}

À CAPES, pela bolsa de mestrado concedida a Viviani Correia; ao $\mathrm{CNPq}$, pela bolsa de produtividade em pesquisa do Prof. João Radünz Neto; aos alunos e aos professores do Laboratório de Piscicultura e Núcleo Integrado de Análises Laboratoriais da UFSM, pelo apoio na condução do trabalho.

\section{REFERÊNCIAS}

ABELHA, M.C.F.; AGOSTINHO, A.A.; GOULART, E. Plasticidade trófica em peixes de água doce. Acta Sci. Anim. Sci., v.23, p.425-434, 2001.

ARANA, L.V. Princípios químicos de qualidade da água em aquicultura: uma revisão para peixes e camarões. Florianópolis: UFSC, 2004. 231p.
BERGAMIN, G.T.; RADÜNZ NETO, J.; EMANUELLI, T. et al. Substituição da farinha de carne suína por fontes vegetais em dietas para carpa-húngara. Pesq. Agropec. Bras., v.45, p.1189-1197, 2010.

BLIGH, E.G.; DYER, W.J. A rapid method of total lipid extraction and purification. Can. J. Biochem. Phys., v.37, p.911-917, 1959.

BOSCOLO, W.R.; SIGNOR, A.; SIGNOR, A.A. et al. Inclusão de amido em dietas para larvas de tilápia-do-nilo. Rev. Bras. Zootec., v.37, p.177180, 2008.

BURKERT, D.; ANDRADE, D.R.; SIROL, R.N. et al. Rendimentos do processamento e composição química de filés de surubim cultivado em tanques-rede. Rev. Bras. Zootec., v.37, p.1137-1143, 2008.

CHAMPE, P.C.; HARVEY, R.A. Bioquímica Ilustrada. 2.ed. São Paulo:Artes Médicas, 1997. $446 \mathrm{p}$.

CONTRERAS-GUZMÁN, E.S. Bioquímica de pescados e derivados. Jaboticabal: FUNEP, 1994. 409 p.

FRANCIS, G.; MAKKAR, H.P.S.; BECKER, K. Antinutritional factors present in plant-derived alternate fish feed ingredients and their effects in fish. Aquaculture, v.199, p.197-227, 2001.

HEMRE, G-I.; HANSEN, T. Utilization of different dietary starch sources and tolerance to glucose loading in Atlantic salmon (Salmo salar), during parr-smolt transformation. Aquaculture, v.161, p.145-157, 1998.

HEMRE, G-I.; MOMMSEN, T.P.; KROGDAHL, A. Carbohydrates in fish nutrition: effects on growth, glucose metabolism and hepatic enzymes. Aquac. Nutr., v.8, p.175-194, 2002.

KROGDAHL, A.; HEMRE, G.I.; MOMMSEN, T.P. Carbohydrates in fish nutrition: digestion and absorption in postlarval stages. Aquac. Nutr., v.11, p.103-122, 2005.

KUBOTA, E.H.; EMANUELLI, T. Processamento do pescado. In: BALDISSEROTTO, B.; RADÜNZ NETO, J. Criação de Jundiá. Santa Maria: Ed.UFSM, 2004. p.201-228. 
LAZZARI, R.; RADÜNZ NETO, J.; EMANUELLI, $\mathrm{T}$. et al. Diferentes fontes protéicas para a alimentação do jundiá (Rhamdia quelen). Cienc. Rural, v.36, p.240-246, 2006.

MEURER, F. Milheto em rações para a tilápiado-nilo (Oreochromis niloticus) durante a reversão sexual. Acta Sci. Anim. Sci., v.26, p.323-327, 2004.

MEYER, G.; FRACALOSSI, D.M.; BORBA, M.R. A importância da quantidade de energía na ração de peixes. Panorama Aquic., v.14, p.5357, 2004.

NAGAE, M.Y.; HAYASHI, C.; GALDIOLI, E.M. Inclusão do triticale em rações para alevinos de piavuçu, Leporinus macrocephalus (Garavello e Britski, 1988). Acta Sci. Anim. Sci., v.23, p.849-853, 2001.

OFFICIAL methods of analysis. 16.ed. Washington: AOAC, 1995. 1018 p.

PEDRON, F.A.; RADÜNZ NETO, J.; EMANUELLI, T. et al. Cultivo de jundiás alimentados com dietas com casca de soja ou de algodão. Pesq. Agropec. Bras., v.43, p.93-98, 2008.

PESTANA, V.R.; MENDONÇA, C.R.B.; ZAMBIAZI, R.C. Farelo de arroz: características, benefícios à saúde e aplicações. Bol. Cent. Pesq. Process. Aliment., v.26, p.29-40, 2008.
PETERSON, D.M. Oat antioxidants. J. Cereal Sci., v.33, p.115-129, 2001.

PRZYBYL, A.; MAZURKIEWICZ, J. Nutritive value of cereals in feeds for common carp (Cyprinus carpio). Czech J. Anim. Sci., v.49, p.307-314, 2004.

SIGNOR, A.A.; BOSCOLO, W.R.; FEIDEN, A. et al. Triguilho na alimentação da tilápia-do-nilo (Oreochromis niloticus L.): digestibilidade e desempenho. Cienc. Rural, v.37, p.1116-1121, 2007.

SVIHUS, B.; UHLEN, A.K.; HARSTAD, O.M. Effect of starch granule structure, associated components and processing on nutritive value of cereal starch: A review. Anim. Feed Sci. Technol., v.122, p.303-320, 2005.

VALENTE, L.M.P.; OLMEDO, M.; BORGES, P. et al. Effects of carbohydrate sources on growth, body composition and tissue lipid deposition of blackspot seabream, Pagellus bogaraveo (Brunnich). J. Anim. Physiol. Nutr., v.94, p.212-219, 2009.

WEBSTER, C.D.; LIM, C. Introdution to fish nutrition. In: WEBSTER, C.D.; LIM, C. Nutrient Requirement and Feeding of Finfish for Aquaculture. London: CABI Publishing, 2002. Cap. 1, p.1-27. 